\title{
The Hippo signaling pathway in leukemia: function, interaction, and carcinogenesis
}

\author{
Negar Noorbakhsh', Bentolhoda Hayatmoghadam², Marzieh Jamali³, Maryam Golmohammadi and \\ Maria Kavianpour ${ }^{5^{*}}$ (1)
}

\begin{abstract}
Cancer can be considered as a communication disease between and within cells; nevertheless, there is no effective therapy for the condition, and this disease is typically identified at its late stage. Chemotherapy, radiation, and molecular-targeted treatment are typically ineffective against cancer cells. A better grasp of the processes of carcinogenesis, aggressiveness, metastasis, treatment resistance, detection of the illness at an earlier stage, and obtaining a better therapeutic response will be made possible. Researchers have discovered that cancerous mutations mainly affect signaling pathways. The Hippo pathway, as one of the main signaling pathways of a cell, has a unique ability to cause cancer. In order to treat cancer, a complete understanding of the Hippo signaling system will be required. On the other hand, interaction with other pathways like Wnt, TGF- $\beta$, AMPK, Notch, JNK, mTOR, and Ras/MAP kinase pathways can contribute to carcinogenesis. Phosphorylation of oncogene YAP and TAZ could lead to leukemogenesis, which this process could be regulated via other signaling pathways. This review article aimed to shed light on how the Hippo pathway interacts with other cellular signaling networks and its functions in leukemia.
\end{abstract}

Keywords: Hippo signaling pathway, Signaling, Leukemia, Hematologic neoplasms, Cancer

\section{Introduction}

Hematological malignancies include lymphoma, myeloma, myeloproliferative neoplasms, myelodysplastic syndromes, and leukemia with several subtypes [1]. Leukemia is divided into lymphocytic and myeloid, which these two mentioned groups include acute and chronic groups. In total, leukemia is a clonal disorder that results from genetic and epigenetic changes in a hematopoietic stem or progenitor cells that disrupt main processes such as self-renewal, proliferation, and differentiation $[2,3]$. Leukemic stem cells have several critical signaling pathways regulating stem or progenitor cell proliferation, hematopoiesis, self-renewal, tissue repair, and apoptosis $[4,5]$. Cell numbers are based on signaling pathways

*Correspondence: Kavianpour.maria@gmail.com

${ }^{5}$ Department of Applied Cell Sciences, School of Advanced Technologies in Medicine, Tehran University of Medical Sciences, Tehran, Iran

Full list of author information is available at the end of the article that communicate extracellular and intracellular stimuli to gene transcription. For example, constitutive and cytokine-mediated activation of the PI3K/Akt/mTOR signaling pathway is a common hallmark in patients with acute myeloid leukemia (AML), and regulation of this system is a feasible therapeutic option in the treatment of AML $[4,6]$.

A new signaling pathway, Hippo, has played a crucial role in maintaining organ size by regulating cell proliferation and death in the last decade [7]. Due to the severe overgrowth phenotype, Drosophila mosaic genetic screens first found many mutations in the Hippo signaling pathway [8]. Because of its remarkable effectiveness in controlling organ size, as well as its apparent significance to tissue regeneration and cancer, the Hippo signaling pathway immediately has drawn widespread interest [9]. Mammalian sterile 20-like 1/2 (MST1/2, also known STK4/3), Salvador (SAV1), Large tumor suppressor homolog $1 / 2$ original author(s) and the source, provide a link to the Creative Commons licence, and indicate if changes were made. The images or other third party material in this article are included in the article's Creative Commons licence, unless indicated otherwise in a credit line to the material. If material is not included in the article's Creative Commons licence and your intended use is not permitted by statutory regulation or exceeds the permitted use, you will need to obtain permission directly from the copyright holder. To view a copy of this licence, visit http://creativecommons.org/licenses/by/4.0/. The Creative Commons Public Domain Dedication waiver (http://creativeco mmons.org/publicdomain/zero/1.0/) applies to the data made available in this article, unless otherwise stated in a credit line to the data. 
(LATS1/2), MOB kinase activator 1A/B (MOB1a/b), and Yes-associated protein (YAP)/Transcriptional coactivator with PDZ binding motif (TAZ, also known WWTR1) are the mammalian orthologs of Hpo, Sav, Wts, Mats, and Yki, respectively [10].

Furthermore, a mutation in the genes encoding Hippo signaling proteins can cause significant organ shape or growth parameters $[11,12]$. For example, renal cell carcinoma [13], pancreatic cancer [14], breast cancer [15], cholangiocarcinoma [16], medulloblastoma [17], and hepatocellular cell carcinoma (HCC) [18] have all been found to have an abnormal expression of YAP [19-21]. After analyzing 177 pairs of HCC, standard samples with comprehensive clinical data were matched; it was revealed HCC patients with YAP have an independent prognostic marker for overall survival and disease-free survival [22].

There is insufficient evidence to identify the tissue specificity and frequency of pathway components and YAP mutations in human leukemias [23]. Several hematological malignancies have been linked to abnormal expression or genetic deficiencies in the Hippo signaling pathway, including acute leukemia and lymphoproliferative neoplasms $[24,25]$. For example, in a study by Chen et al. they measured the effects of YAP knockdown on HL-60 cells. Their study found that inhibition of YAP inhibits proliferation and induces apoptosis in the cell line [25]. YAP was also overexpressed in CML cells in Li et al's study and inhibiting this protein reduced CML cell growth, triggered apoptosis, and lowered the expression of YAP target genes c-Myc and survivin. As a result, YAP could play a key role in CML cell proliferation and leukemogenesis. The genetic or pharmacological suppression of YAP offers a potential CML therapeutic option [26].

The standard of care for leukemia depends on many factors chosen based on age and overall health, the type of leukemia, and the stage of the disease [27]. Common treatments used to fight leukemia include chemotherapy, targeted therapy, radiation therapy, bone marrow transplant, immunotherapy, and engineering immune cells. Despite advances and extensions in existing treatments, leukemia is associated with low survival rates and poor prognosis in some cases [28]. Some patients resist the usual treatments, and some relapse after remission induction [29]. Therefore, a search in this signaling pathway is needed to find a new treatment strategy. In this study, we intend to address the Hippo signaling pathway, its interaction with other pathways, and its importance in different types of leukemia; perhaps by providing important and effective proteins, this signaling pathway provides a novel treatment strategy for leukemia.

\section{Normal function of Hippo signaling pathway}

The human Hippo pathway is based on a kinase signaling cascade including MST1 and MST2, as well as LATS1/2, SAV1 and MOB1, are two types of serine/ threonine kinases [30]. When the Hippo pathway is inactive, unphosphorylated YAP/TAZ enters the nucleus and interacts with TEA DNA-binding proteins (TEAD1-4), then target genes regulated by this complex [31, 32] (Fig. 1). It is also proteolytically degraded when the Hippo pathway is activated [30, 33]. The Hippo pathway is dysregulated in cancer, enabling hyperproliferation, cellular invasion, metastasis, and chemoresistance [7, 34] (Fig. 1).

\section{Prognostic value of YAP in cancer}

The level of YAP1 protein is elevated a variety of cancers, including colorectal cancer (CRC), gastric cancer, esophageal squamous cell cancer (ESCC), human hepatocellular carcinoma (HCC), osteosarcoma [35-38]. The Hippo pathway can be promoted by YAP1 influence across multiple signaling pathways. Many studies have recently examined how tumorigenesis, tumor growth,, epithelial to mesenchymal transition (EMT), resistance to apoptosis and cancer prognosis are all affected by YAP1 [39]. YAP1 facilitates the growth of tumor cells and can lead to a poor prognosis in many cancers. Additionally, YAP1, a tumor suppressor, has been identified as an apoptotic factor induced by DNA damage in collaboration with $\mathrm{p} 73$ and promyelocytic leukemia [40, 41]. In CRC, YAP expression was associated to TNM stage, and expression level of cyclin D1; Wang et al. found that YAP expression was also linked to a short overall survival (OS) [42].

$\mathrm{Qu}$ et al. reported that downregulating YAP inhibited cell migration and invasion, and YAP expression level could be a new marker for predicting the prognosis of patients with ESCC [36]. According to Xia et al. high levels of YAP expression were positively correlated with TEAD4 gene expression in ovarian cancer patients [43]. As Barry et al. reported, complete loss of YAP was associated with poorer patient survival and high-grade, stage IV disease than YAP-positive groups. Furthermore, they found that YAP could act independently to restrict Wnt signaling [44]. A meta-analysis assessed the relationship between YAP1 expression and overall survival (OS) in 20 studies that was conducted on 2067 patients. As a result of this study, it is statistically significant that positive YAP1 expression can negatively impact OS and diseasefree survival (DFS) in patients with cancer. It's also been claimed that YAP1 could behave as a tumor suppressor gene in some cancers, which would be a poor prognostic factor [45]. 


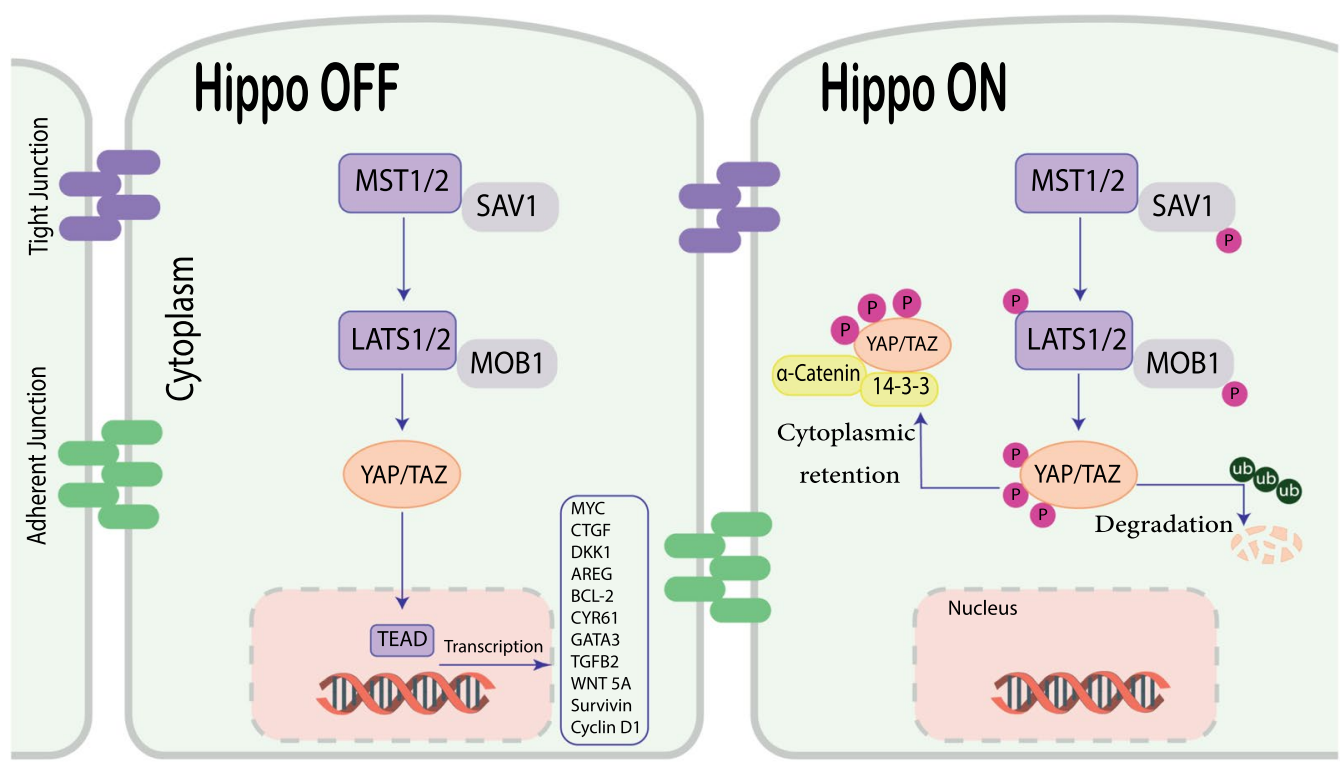

Fig. 1 The core of the Hippo pathway. Multiple upstream signals regulate phosphorylation when the Hippo signaling pathway is activated, and MST1/2 kinases and SAV1 form a complex to phosphorylate and activate LATS1/2. YAP/TAZ proteins, two important downstream effectors of the Hippo pathway, are phosphorylated by LATS1/2 kinases. Phosphorylation of YAP/TAZ triggers the recruitment of 14-3-3 proteins, which promote cytoplasmic retention or proteolytic destruction. YAP/TAZ is not phosphorylated, localizes to the nucleus, forms a complex with transcription factor TEADs, and controls genes needed for endothelial cell proliferation, migration, and survival when the Hippo signaling pathway is turned off. LATS1/2 large tumor suppressor kinase; MST1/2 mammalian ste20-like kinase; SAV1 scaffold protein salvador; TAZ transcriptional co-activator with PDZ-binding motif; TEADTEA domain family member; YAPYes-associated protein

\section{The effect of Hippo signaling pathway in carcinogenesis}

A wide range of upstream stimuli such as extracellular ligands, organ size, mechanotransduction, environmental stress, energy stress, and cell-cell contact controls YAP/TAZ activation in cancer cells [46]. The activation of YAP/TAZ via the dysregulation of the Hippo pathway is responsible for tumor development and confers cancer stem cell characteristics such as anoikis resistance, epithelial-to-mesenchymal transition, drug resistance, energy stress, and metastasis [47] (Fig. 2).

\section{Hippo signaling pathway and interaction with other signaling pathways}

Increased tissue development has been connected to YAP protein activation, as well as direct target genes like Myc, cell cycle regulators like $\mathrm{CycE}$ and E2F1, and apoptosis inhibitors like Diap1 and BIRC3, which have all been identified as contributory factors [48]. Other signaling pathways that may play a role in tissue growth control, including as the Wnt, Notch, EGFR, TGF, and Jak-STAT pathways, have also been identified as YAP protein targets [49] (Fig. 3). Upstream components of the Hippo pathway that adversely inhibit YAP activity, such as Merlin, Expanded, Kibra, AMOTL2, and LATS

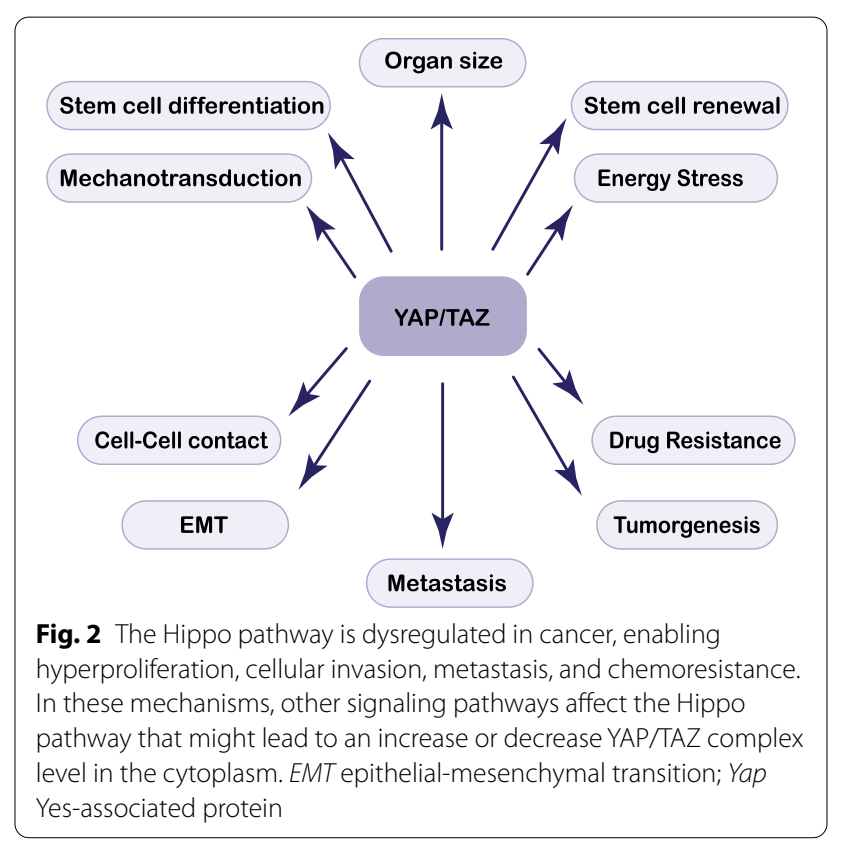

kinases, are another family of transcriptional targets [50]. Thousands of new potential targets have been discovered according to genome-wide expression profiling and chromatin binding. However, there are significant 


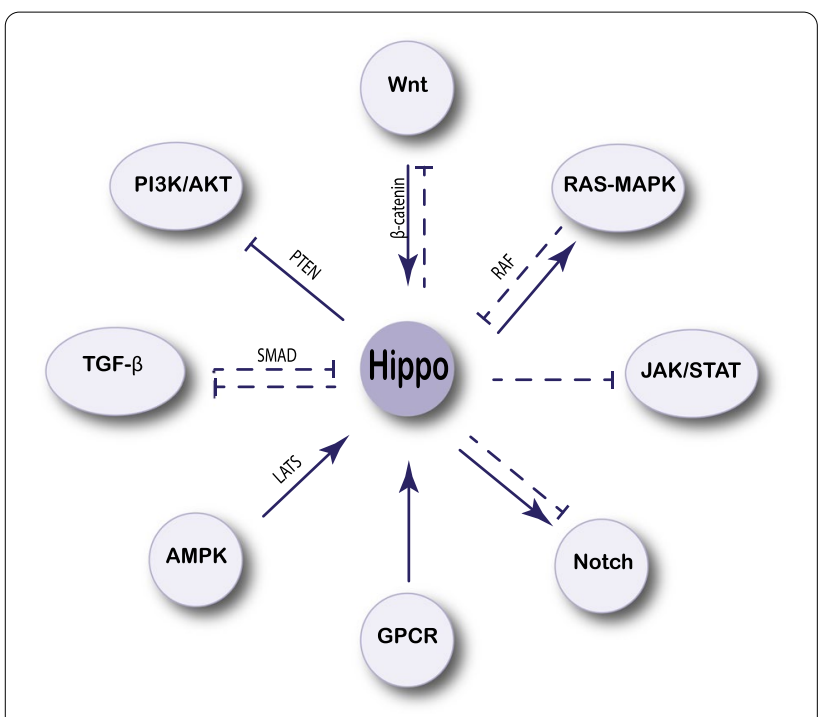

Fig. 3 The Hippo pathway interacts with other signaling pathways. Akt protein kinase B; AMPK AMP-activated protein kinase; GPCR G protein-coupled receptor; JAK-STAT janus kinase and signal transducer and activator of transcription; MAPK mitogen-activated protein kinase; PI3K phosphatidylinositol-3-kinase; RAS rat sarcoma; SMAD mothers against decapentaplegic homolog; TGF transforming growth factor

discrepancies between the lists of targets discovered in research involving various cell types, implying that much of the YAP response is tissue or cell-type specific [50,51]. The transcription of several genes involved in cell proliferation, differentiation, and growth could be affected by these relationships. In this part, we looked at how Hippo signaling interacts with other important pathways in leukemia.

\section{Hippo and Wnt signaling pathways}

In HSCs, Wnt signaling is critical for maintaining homeostasis $[52,53]$. Low levels of Wnt activation promote hematopoietic stem cell (HSC) function, whereas high Wnt doses reduce hematopoiesis, demonstrating that canonical Wnt signaling regulates hematopoiesis in a dose-dependent manner [54]. As a result, the HSC requires a precisely controlled quantity of Wnt signaling pathway activity for self-renewal, survival, growth, and proliferation [55]. The stimulation of Wnt signaling is a frequent, varied feature of all leukemia types. For example, individuals with FLT3-mutated AML have high amounts of $\beta$-catenin, promoting in vivo leukemia growth in xenograft mice reconstituted AML cell lines with del(5q) [56]. Furthermore, abnormal expression of Wnt pathway components such as WNT1, WNT2b, and LEF-1 is found in many AML cases, so Wnt signaling has a predictive value in AML [57].
The canonical Wnt pathway is CML's most seriously impacted Wnt system [58]. Because the fusion protein BCR-ABL may actively adjust $\beta$-catenin levels in cells. In CML progenitors, nuclear $\beta$-catenin increased resistance to intrinsic tyrosine kinase inhibitor (TKI) [59]. In CML, FoxM1/ $\beta$-catenin interaction is essential for controlling canonical Wnt signaling and cancer stem cell selfrenewal, proliferation, and tumorigenesis [60].

According to accumulating evidence, YAP/TAZ, the key effectors in the Hippo signaling cascade, regulate $\beta$-catenin levels and activity by physically interacting with $\beta$-catenin or Dvl. The first clear evidence that YAP/ TAZ inhibited the Wnt/ $\beta$-catenin pathway came from a study identifying TAZ's direct interaction with Dvl in the cytoplasm. After Wnt3a stimulation, TAZ knockdown increased Dvl phosphorylation, consequently increasing the nuclear accumulation of $\beta$-catenin. Suppressing an upstream kinase in the Hippo pathway improved the connection between TAZ and Dvl, resulting in Wnt/ $\beta$ catenin pathway downregulation [61]. TAZ's role as a modulator of $\mathrm{Wnt} / \beta$-catenin signaling is an interesting hypothesis. The $\beta$-catenin destruction complex, which is made up of APC, Axin, and GSK3, has been demonstrated to modulate TAZ levels. $\beta$-catenin phosphorylated by GSK3 functions as a scaffold for the interaction of TAZ with the TrCP E3 ligase complex in the absence of Wnt signaling [62]. Wnt3a was also discovered to cause TAZ dephosphorylation and stabilization, allowing TAZ to be more easily localized in the nucleus.

Because Wnt signaling is essential in leukemia stem cells and the microenvironment, targeting Wnt signaling pathways could help treat leukemia [63]. Wnt and Hippo signaling pathways control similar biological processes; therefore, they could regulate each other's activity for precise systems biology rather than function [64]. Furthermore, YAP can be developed as a novel treatment target based on the two pathways by the intersection of these two signaling pathways (Fig. 3).

\section{Hippo pathway and mTOR interconnection}

The cellular energy levels, amino acids, and other nutrients affect the rapamycin (mTOR) pathway [65]. Also, it is a master regulator of cell growth and metabolism and is an essential downstream effector of PI3K/AKT [66]. In recent trials, rapamycin and its analogs have shown significant anti-cancer activity in hematologic malignancies.

Given the importance of Hippo and mTOR signaling in growth control, it is not unexpected that links between them have been discovered. Mutation of the tuberous sclerosis complex (TSC), a critical negative regulator of $\mathrm{mTORC} 1$, resulted in an $\mathrm{mTOR}$ and autophagy-dependent overexpression of YAP proteins in a mouse cancer model [67]. mTORC2 phosphorylation 
Table 1 Expression level of Hippo signaling pathway components in studies of leukemia

\begin{tabular}{|c|c|c|c|c|c|c|c|}
\hline Hippo components & Expression level & Cancer type & No patients & Significant value & Samples & P value & References \\
\hline Lats2 & \multirow[t]{4}{*}{ Overexpression } & \multirow[t]{4}{*}{ CML } & \multirow[t]{4}{*}{67} & \multirow{4}{*}{$\begin{array}{l}\text { Diagnosis marker, good } \\
\text { prognosis and improve } \\
\text { treatment response }\end{array}$} & \multirow[t]{4}{*}{ PBMC } & \multirow[t]{4}{*}{$<0.05$} & \multirow[t]{4}{*}{ [104] } \\
\hline Aurka & & & & & & & \\
\hline Taz & & & & & & & \\
\hline Aurkb & & & & & & & \\
\hline Mst1 & \multirow[t]{3}{*}{ No change } & \multirow[t]{3}{*}{ AML } & \multirow[t]{3}{*}{52} & \multirow[t]{3}{*}{-} & \multirow[t]{3}{*}{ PBMC } & \multirow[t]{3}{*}{$>0.05$} & \multirow[t]{3}{*}{ [105] } \\
\hline Mst2 & & & & & & & \\
\hline Yap1 & & & & & & & \\
\hline Mst1 & Downregulation & $\begin{array}{l}\text { Animal model of lym- } \\
\text { phoma and leukemia }\end{array}$ & - & $\begin{array}{l}\text { Ability to prevent chromo- } \\
\text { somal instability }\end{array}$ & Lymphocytes & $<0.05$ & [106] \\
\hline Yap & Overexpression & Leukemia and lymphoma & - & Proliferation & Jurkat cell line & $<0.05$ & [21] \\
\hline Lats2 & Overexpression & $\mathrm{AML}$ & 32 & Cancer development & PBMC & $<0.05$ & [86] \\
\hline Yap & Overexpression & CML & - & $\begin{array}{l}\text { Proliferation and leukemo- } \\
\text { genesis }\end{array}$ & BMMNCS & $<0.05$ & [26] \\
\hline Lats2 & Downregulation & ALL & 101 & Prognostic value & BMMNCs & $<0.05$ & [87] \\
\hline Mobkl2a & \multirow[t]{3}{*}{ Downregulation } & \multirow[t]{3}{*}{$\mathrm{MCL}$} & \multirow[t]{3}{*}{77} & \multirow{3}{*}{$\begin{array}{l}\text { Pathogenetic role for } \\
\text { cancer development }\end{array}$} & \multirow[t]{3}{*}{ Lymph node } & \multirow[t]{3}{*}{$<0.05$} & \multirow[t]{3}{*}{ [107] } \\
\hline Mobkl2b & & & & & & & \\
\hline Lats2 & & & & & & & \\
\hline
\end{tabular}

AL acute leukemia; $A L L$ acute lymphocytic leukemia; $A M L$ acute myeloid leukemia; $A U R K A / B$ aurora kinase $A / B$; $B M-M n c s$ bone marrow mononuclear cells; $C L L$ chronic lymphocytic leukemia; CML chronic myelogenous leukemia; LATS2: large tumor suppressor kinase 2; MST1 macrophage stimulating 1; MCL mantle cell lymphoma; MOBKL2A Mps one binder kinase activator-like 2A; PBMCS peripheral blood mononuclear cells; SMZL splenic marginal zone lymphoma; YAP1 Yes-associated protein 1

reduces AMOT-YAP interaction, resulting in increased expression of YAP target genes [68]. In Drosophila, TOR suppression caused by genetic or dietary deficiency decreased Yki's ability to access its target genes in the nucleus via an unknown mechanism [69]. Various signals can modulate the Hippo signaling in cancer stem cells, which are crucial in tumorigenesis.

\section{The Ras/MAPK and Hippo signaling pathways}

This signaling pathway is critical for transmitting proliferative signals from receptors on membrane-bound [70]. In human cancers, RAS-MAPK pathway genes with canonical strong activating somatic mutations are observed in AMLs [71]. They could influence pathway components and upstream activators such as NRAS, KRAS, BRAF, PTPN11, and FMS-related tyrosine kinase 3 (FLT3), as well as chromosomal translocations in leukemia (for example, BCR-ABL and TEL-PDGFR) [72]. CRAF (RAF-1), BRAF, and ARAF are the three members of the RAF family of serine/threonine kinases [73], and RAF-1 has also been discovered to function in MAPK pathway activation and STK3, also known as MST-2, is a serine/threonine kinase that regulates apoptosis [73]. MST-2 is one of the most important components of the Hippo pathway in mammals [74]; besides, MST-2 and YAP/TAZ are essential Hippo pathway effectors that have been linked to melanoma cell metastatic and invasive abilities [73].
YAP has also been shown to affect how cancer cells respond to inhibitors of the MAPK pathway $[75,76]$. Tumorigenesis is the result of a complex interaction between a number of variables and pathways [77] (Fig. 3). The RAF-1/MST-2 connection, according to studies, could be a novel link between the MAPK and Hippo pathways. Ras (or Ras-related molecules), Raf, MEK, and ERK inhibition may be useful in the treatment of leukemia [78]. Many inhibitors have been applied for clinical trials or are under consideration by the pharmaceutical industry to target essential components of this system [79] (Fig. 3).

\section{Hippo signaling pathway in leukemia}

Deregulation of the Hippo signaling pathway is related to various solid tumors, including lung, breast, liver, and ovary [80]. Signaling pathways alteration can cause Leukemia, and among them, the Hippo pathway possesses significant effects on leukemia tumorigenesis [81]. The Hippo signaling pathway is an essential conservative pathway that helps regulate cell proliferation and apoptosis. Aberrant expression and mutation of core components in the Hippo signaling pathway such as MST1/2, LATS1/2, YAP, and TAZ easily promote cancer cell migration, invasion, and malignancy [82].

Many of the Hippo signaling pathway's genes have been identified as tumor suppressors, such as MST1/2, SAV1, MOB1a/b, and LATS1/2, whereas others, such as YAP/ TAZ, are oncogenes that stimulate malignant cells and 
allow them to proliferate uncontrollably [83]. Several studies have indicated that the activation of this pathway can be seen in many leukemia patients [84] (Table 1).

YAP and TAZ are functional effectors that regulate gene expression by co-activating various transcription factors involved in leukemogenesis, such as RUNX, TEADS, and SMADS [81, 85]. In Gholami et al. the expression analysis of LATS2 as a tumor suppresser gene in de novo AML subjects has revealed that LATS2 may be correlated with leukemogenesis. LATS2 gene was significantly overexpressed in patients who suffered AML compared to normal subjects [86] (Table 1). Another study revealed the MST2-ETV6 fusion gene as a core component of the Hippo signaling system, a possible oncogene, in AML patients with $t(8 ; 12)$ translocation [81].

In line with AML, Acute lymphocytic leukemia (ALL) low expression of the LATS2 gene was associated with ALL patients. Jimenez-Velasco et al. in their research, showed that low expression of the LATS2 gene is linked to promoter region methylation in leukemia cells [87] (Table 1). MST1 deficiency has also been shown to enhance T-cell ALL in the presence of mutagenic stimulation in other studies. MST1 deletion mice also develop lymphomas faster, and lymphocytes have been found to have chromosomal instability. KIBBRA, a critical upstream component in the Hippo signaling pathway, is heavily methylated, and this is the crucial underlying leukemogenesis event in this subtype of leukemia [21].

Also, chronic lymphocytic Leukemia (CLL) studies demonstrated that YAP mRNA expression was more significant than healthy controls. In CLL, characterized as lymphoma with B cell accumulation in the blood, bone marrow, and lymph nodes, epigenetic modulation of WWC1 expression was also observed. The WWC1 gene was methylated in around one-third of CLL patients' samples, resulting in lower WWC1 expression [84]. YAP is overexpressed in patients' chronic myelogenous leukemia (CML) cells. Hui li et al. found that the expression level of YAP is significantly higher in CML patients' bone marrow mononuclear cells, indicating that YAP plays a critical role in CML leukemogenesis. The result of another survey has revealed that LATS2 and AURKA, as well as TAZ and AURKB at advanced phases, are overexpressed compared to healthy control groups, which powerfully demonstrate the role of this signaling pathway deregulation in the pathogenesis of CML patients [26] (Table 1).

\section{Crosstalk between the Hippo pathway and miRNAs}

MicroRNAs are highly involved in the Hippo pathway regulation. Several studies have shed light on the role of the Hippo pathway in tumorigenesis in various types of cancer such as breast, liver, gastric, glioblastoma cancers [88]. Importantly, miRNAs have been revealed to directly target and regulate the core components of the Hippo pathway. For example, miR-874-3p is significantly downregulated in colorectal cancer (CRC) tissue compared to normal tissues. MiR-874-3p by inhibition the YAP expression in the Hippo pathway resulting in the inactivation of the TEAD transcription [89]. Another research has revealed that miR-665 could promote proliferation and metastasis in hepatocellular carcinoma by inhibiting Hippo pathway activity [90]. In leukemia patients, which is the main topic of our article, several studies have been conducted to address the pivotal role of different microRNAs on the regulation of Hippo pathway components [91]. miR-550-1 acts as a tumor suppressor through the Hippo signaling pathway in AML. In a survey, microarray analysis revealed that miR-550-1 was significantly downregulated in the AML sample from the human patients, probably due to hypermethylation of the associated CpG islands. WWTR1 gene is considered a downstream target

Table 2 The contribution of microRNAs demonstrated to be involved in the Hippo pathway in leukemia

\begin{tabular}{|c|c|c|c|c|c|}
\hline MicroRNAs & Expression level & Cancer type & Significant value & Samples & References \\
\hline \multirow[t]{2}{*}{ miR-9 } & Downregulated & AML & Activating Hippo/YAP signaling & Cell lines (THP-1, HL-60, TF-1, KG-1) & [108] \\
\hline & & & Restrain the sharp increase boost apoptosis & & \\
\hline \multirow[t]{2}{*}{ miR-550-1 } & Downregulated & AML & $\begin{array}{l}\text { WWTR1 gene was a downstream target of miR-550- } \\
1\end{array}$ & Cell lines (MV4-11, Kasumi-1 cells) & [92] \\
\hline & & & $\begin{array}{l}\text { Disrupted the proliferation and tumorigenesis of } \\
\text { AML cells }\end{array}$ & & \\
\hline miR-181a & Downregulated & CML & Decreased activation of YAP & & [109] \\
\hline \multirow[t]{2}{*}{ miR-7977 } & - & AML & $\begin{array}{l}\text { miR-7977 inactivated the Hippo-YAP signaling } \\
\text { pathway }\end{array}$ & Human BM CD34 + cells & [110] \\
\hline & & & $\begin{array}{l}\text { miR-7977 significantly reduced the expression of } \\
\text { Hippo core kinase, STK4, YAP/TEAD }\end{array}$ & & \\
\hline
\end{tabular}




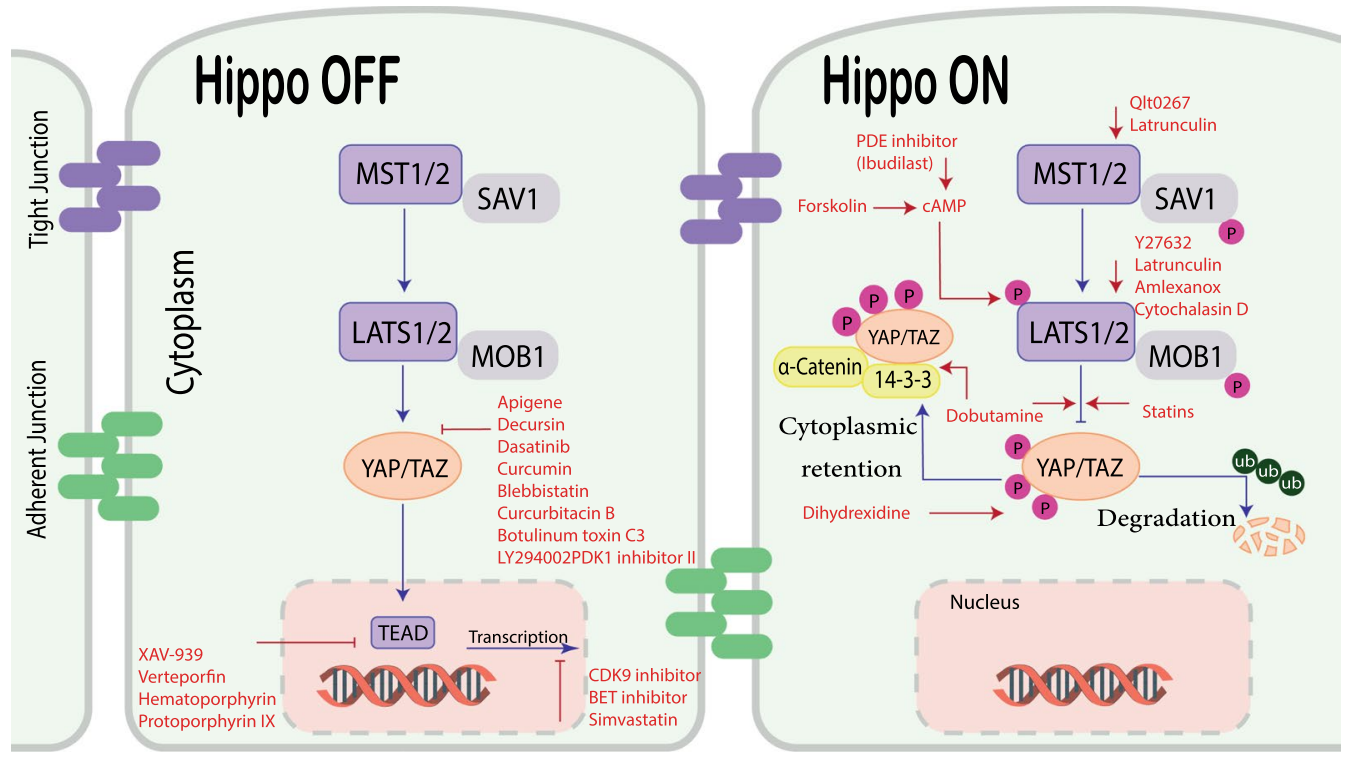

Fig. 4 New druggable agent effective in targeting YAP. The figure shows the drug agents that can be effective in the Hippo signaling pathway. Some of these drugs inhibit YAP/TAZ nuclear localization or block the transcription of target genes. Some others lead to the degradation of these proteins by increasing LATS activity and phosphorylation of the YAP/TAZ complex. LATS large tumor suppressor kinase; Yap Yes-associated protein

of miR-550-1, reducing the WWTR1 stability [92]. The information of the other microRNAs that contributed to the Hippo pathway in leukemia is described in Table 2.

\section{New pharmacological inhibitor targeting YAP}

Despite advances in cancer treatment in recent decades, most patients respond poorly after a certain number of treatment cycles, and researchers also face significant challenges in treating cancer [93]. We summarize the pharmacological agents targeting the Hippo pathway to eliminate cancer cells. Dasatinib and statins represent compounds that inhibit YAP/TAZ activity via activating LATS [94]. Verteporfin represents compounds that inhibit the interaction between YAP/TAZ and TEAD [95]. Blebbistatin, Botulinum toxin C3 and LY294002PDK1 inhibitor II inhibit YAP/TAZ nuclear localization and transcriptional activity [96, 97]. Discoveries imply the suppression of YAP/TAZ-driven transcription via CDK9 inhibitors [98].

Simvastatin also has a potent YAP/TAZ inhibiting action. Ibudilast (a PDE4 selective inhibitor) and Forskolin can promote YAP phosphorylation by preventing cAMP breakdown, implying that PDE inhibitors may be useful in the treatment of cancers with YAP oncogenic activity [99, 100]. Dobutamine's possible anti-cancer activity was recently investigated in a variety of cancer types. Dobutamine causes phosphorylation of YAPSer127, which causes YAP-dependent gene transcription to be suppressed [101]. Latrunculin B and cytochalasin D, which disrupt the actin cytoskeleton, limit YAP activation in response to cell attachment to the ECM-Inhibition of nuclear YAP localization via increased LATS activity [102]. Dihydrexidine increases YAP phosphorylation and inhibits Hippo signaling pathway [103] (Fig. 4).

\section{Conclusion and future perspective}

Hippo signaling plays an important role in tumor initiation, invasion, drug resistance, metastatic potential, and self-renewal of cancer stem cells, as well as developmental control. According to studies on this signaling pathway, YAP as a tumor suppressor gene can be involved in many types of cancer. In leukemias, although not much information is available, the increased expression of this protein shows a significant relationship with the poor prognosis of patients. Therefore, the study of the mechanism of action YAP and the factors affecting its inhibition in cancer can be proposed as new pharmacological agents in leukemia treatment.

\footnotetext{
Abbreviations

Akt: Protein kinase B; ALL: Acute lymphocytic leukemia; AML: Acute myeloid leukemia; AMPK: AMP-activated protein kinase; APC: Adenomatous polyposis coli; APL: Acute promyelocytic leukemia; AURKA/B: Aurora kinase A/B; CRC : Colorectal cancer; CLL: Chronic lymphocytic leukemia; CML: Chronic myelogenous leukemia; DVL: Dishevelled; ERK: Extracellular signal-regulated kinase; FOXH1: Forkhead box H1; GLUT3: Glucose transporter 3; GSK3B: Glycogen synthase kinase 3 beta; HCC: Hepatocellular carcinoma; HSC: Hematopoietic stem cell; JNK: Jun N-terminal kinase; LATS2: Large tumor suppressor kinase 2; LEF1: Lymphoid enhancer binding factor 1; LKB1: Liver kinase B1; MAP: Mitogen-activated protein; Mats: Mob as tumor suppressor; MEK: MAPK/ERK kinase; MOB1a/b: MOB kinase activator 1A/B; MOBKL2A: Mps one binder kinase activator-Like 2A; MST1/2: Macrophage stimulating 1/2;
} 
mTOR: Mammalian target of rapamycin; KIBRA: Kidney and brain protein; PI3K: Phosphatidylinositol-3-kinase; PTEN: Phosphatase and tensin homolog; Sav: Scaffold protein salvador; SMAD: Mothers against decapentaplegic homolog; STK4/3: Serine/threonine kinase 3/4; TAZ: Tafazzin; TAZ: Transcriptional coactivator with PDZ binding motif; TCF: T-cell factor; TEAD1-4: TEA DNA-binding proteins; TGF: Transforming growth factor; Wts: Protein kinase warts; WWTR1: WW domain-containing transcription regulator protein 1; YAP:Yes-associated Protein; Yki: Yorkie.

\section{Acknowledgements}

Not applicable.

\section{Authors' contributions}

$\mathrm{NN}$ and $\mathrm{MK}$ contributed to the conception, design. $\mathrm{NN}, \mathrm{BH}$, and MJ contributed to data collection and manuscript drafting. MK and MG illustrated the figure, and MK oversaw the study. All authors read and approved the final manuscript.

\section{Funding}

No funding.

\section{Availability of data and materials}

The primary data for this study is available from the authors on direct request.

\section{Declarations}

\section{Ethics approval and consent to participate}

Not applicable.

\section{Consent for publication}

Not applicable.

\section{Competing interests}

The authors declare that they have no competing interests.

\section{Author details}

${ }^{1}$ Behbahan Faculty of Medical Sciences, Behbahan, Iran. ${ }^{2}$ Department of Clinical Biochemistry, School of Pharmacy and Pharmaceutical Sciences, Isfahan University of Medical Sciences, Isfahan, Iran. ${ }^{3}$ Gene Therapy Research Center, Digestive Diseases Research Institute, Tehran University of Medical Sciences, Tehran, Iran. ${ }^{4}$ Applied Cell Sciences and Hematology Department, Faculty of Medical Sciences, Tarbiat Modares University, Tehran, Iran. ${ }^{5}$ Department of Applied Cell Sciences, School of Advanced Technologies in Medicine, Tehran University of Medical Sciences, Tehran, Iran.

\section{Received: 24 August 2021 Accepted: 13 December 2021}

\section{Published online: 25 December 2021}

\section{References}

1. Jian J, Qiao Y, Li Y, Guo Y, Ma H, Liu B. Mutations in chronic myelomonocytic leukemia and their prognostic relevance. Clin Transl Oncol. 2021;23(9):1731-1742. https://doi.org/10.1007/s12094-021-02585-x.

2. Pang WW, Schrier SL, Weissman IL. Age-associated changes in human hematopoietic stem cells. Semin Hematol. 2017;54(1):39-42. https://doi. org/10.1053/j.seminhematol.2016.10.004

3. Kahn JM, Keegan TH, Tao L, Abrahão R, Bleyer A, Viny AD. Racial disparities in the survival of American children, adolescents, and young adults with acute lymphoblastic leukemia, acute myelogenous leukemia, and Hodgkin lymphoma. Cancer. 2016;122(17):2723-30. https://doi.org/10. 1002/cncr.30089.

4. Siveen KS, Uddin S, Mohammad RM. Targeting acute myeloid leukemia stem cell signaling by natural products. Mol Cancer. 2017;16(1):13. https://doi.org/10.1186/s12943-016-0571-x.

5. Riether C, Schürch CM, Ochsenbein AF. Regulation of hematopoietic and leukemic stem cells by the immune system. Cell Death Differ. 2015;22(2):187-98. https://doi.org/10.1038/cdd.2014.89.

6. Nepstad I, Hatfield KJ, Aasebø E, Hernandez-Valladares M, Brenner AK, Bartaula-Brevik S, Berven F, Selheim F, Skavland J, Gjertsen BT, Reikvam
$H$, Bruserud $\varnothing$. Two acute myeloid leukemia patient subsets are identified based on the constitutive PI3K-Akt-mTOR signaling of their leukemic cells; a functional, proteomic, and transcriptomic comparison. Expert Opin Ther Targets. 2018;22(7):639-53. https://doi.org/10.1080/ 14728222.2018 .1487401$.

7. Cho YS, Li S, Wang X, Zhu J, Zhuo S, Han Y, Yue T, Yang Y, Jiang J. CDK7 regulates organ size and tumor growth by safeguarding the Hippo pathway effector Yki/Yap/Taz in the nucleus. Genes Dev. 2020;34(12):53-71. https://doi.org/10.1101/gad.333146.119.

8. Ehmer U, Sage J. Control of Proliferation and Cancer Growth by the Hippo Signaling Pathway. Mol Cancer Res. 2016;14(2):127-40. https:// doi.org/10.1158/1541-7786.

9. Kodaka M, Hata Y. The mammalian Hippo pathway: regulation and function of YAP1 and TAZ. Cell Mol Life Sci. 2015;72(2):285-306. https:// doi.org/10.1007/s00018-014-1742-9.

10. Sebio A, Lenz HJ. Molecular Pathways: Hippo Signaling, a Critical Tumor Suppressor. Clin Cancer Res. 2015;21(22):5002-7. https://doi.org/10. 1158/1078-0432.CCR-15-0411.

11. Irvine KD, Harvey KF. Control of organ growth by patterning and hippo signaling in Drosophila. Cold Spring Harb Perspect Biol. 2015;7(6):a019224. https://doi.org/10.1101/cshperspect.a019224

12. Mach J, Atkins M, Gajewski KM, Mottier-Pavie V, Sansores-Garcia L, Xie J, Mills RA, Kowalczyk W, Van Huffel L, Mills GB, Halder G. Modulation of the Hippo pathway and organ growth by RNA processing proteins. Proc Natl Acad Sci U S A. 2018;115(42):10684-9. https://doi.org/10. 1073/pnas.1807325115.

13. Yin L, Li W, Xu A, Shi H, Wang K, Yang H, Wang R, Peng B. SH3BGRL2 inhibits growth and metastasis in clear cell renal cell carcinoma via activating hippo/TEAD1-Twist1 pathway. EBioMedicine. 2020;51:102596. https://doi.org/10.1016/j.ebiom.2019.12.005.

14. Ren D, Sun Y, Zhang D, Li D, Liu Z, Jin X, Wu H. SGLT2 promotes pancreatic cancer progression by activating the Hippo signaling pathway via the hnRNPK-YAP1 axis. Cancer Lett. 2021;28(519):277-88. https://doi. org/10.1016/j.canlet.2021.07.035.

15. Kim J, Jang G, Sim SH, Park IH, Kim K, Park C. SMARCA4 depletion induces cisplatin resistance by activating YAP1-Mediated epithelialto-mesenchymal transition in triple-negative breast cancer. Cancers (Basel). 2021;13(21):5474. https://doi.org/10.3390/cancers13215474.

16. Xu KD, Miao Y, Li P, Li PP, Liu J, Li J, Cao F. Licochalcone A inhibits cell growth through the downregulation of the Hippo pathway via PES1 in cholangiocarcinoma cells. Environ Toxicol. 2021. https://doi.org/10. 1002/tox.23422.

17. Orr BA, Bai H, Odia Y, Jain D, Anders RA, Eberhart CG. Yes-associated protein 1 is widely expressed in human brain tumors and promotes glioblastoma growth. J Neuropathol Exp Neurol. 2011;70(7):568-77. https://doi.org/10.1097/NEN.0b013e31821ff8d8.

18. Sohn BH, Shim JJ, Kim SB, Jang KY, Kim SM, Kim JH, Hwang JE, Jang HJ, Lee HS, Kim SC, Jeong W, Kim SS, Park ES, Heo J, Kim YJ, Kim DG, Leem SH, Kaseb A, Hassan MM, Cha M, Chu IS, Johnson RL, Park YY, Lee JS. Inactivation of Hippo pathway is significantly associated with poor prognosis in hepatocellular carcinoma. Clin Cancer Res. 2016;22(5):1256-64. https://doi.org/10.1158/1078-0432.CCR-15-1447.

19. Cao JJ, Zhao XM, Wang DL, Chen KH, Sheng X, Li WB, Li MC, Liu WJ, He J.YAP is overexpressed in clear cell renal cell carcinoma and its knockdown reduces cell proliferation and induces cell cycle arrest and apoptosis. Oncol Rep. 2014;32(4):1594-600. https://doi.org/10.3892/or. 2014.3349.

20. Xu MZ, Yao TJ, Lee NP, Ng IO, Chan YT, Zender L, Lowe SW, Poon RT, Luk JM. Yes-associated protein is an independent prognostic marker in hepatocellular carcinoma. Cancer. 2009;115(19):4576-85. https://doi. org/10.1002/cncr.24495.

21. Wu R, Yang H, Wan J, Deng X, Chen L, Hao S, Ma L. Knockdown of the Hippo transducer YAP reduces proliferation and promotes apoptosis in the Jurkat leukemia cell. Mol Med Rep. 2018;18(6):5379-88. https://doi. org/10.3892/mmr.2018.9556.

22. Philippe C, Pinson B, Dompierre J, Pantesco V, Viollet B, DaignanFornier B, Moenner M. AICAR Antiproliferative Properties Involve the AMPK-Independent Activation of the Tumor Suppressors LATS 1 and 2. Neoplasia. 2018;20(6):555-62. https://doi.org/10.1016/j.neo.2018.03. 006. 
23. Li FL, Guan KL. The two sides of Hippo pathway in cancer. Semin Cancer Biol. 2021. https://doi.org/10.1016/j.semcancer.2021.07.006.

24. Oceandy D, Amanda B, Ashari FY, Faizah Z, Azis MA, Stafford N. The Cross-Talk Between the TNF- $a$ and RASSF-Hippo Signalling Pathways. Int J Mol Sci. 2019;20(9):2346. https://doi.org/10.3390/ijms20092346.

25. Chen M, Wang J, Yao SF, Zhao Y, Liu L, Li LW, Xu T, Gan LG, Xiao CL, Shan ZL, Zhong L, Liu BZ. Effect of YAP Inhibition on Human Leukemia HL-60 Cells. Int J Med Sci. 2017;14(9):902-10. https://doi.org/10.7150/ijms. 19965.

26. Li H, Huang Z, Gao M, Huang N, Luo Z, Shen H, Wang X, Wang T, Hu J, Feng W. Inhibition of YAP suppresses CML cell proliferation and enhances efficacy of imatinib in vitro and in vivo. J Exp Clin Cancer Res. 2016;35(1):134. https://doi.org/10.1186/s13046-016-0414-z.

27. Kumar CC. Genetic abnormalities and challenges in the treatment of acute myeloid leukemia. Genes Cancer. 2011;2(2):95-107. https://doi. org/10.1177/1947601911408076.

28. Johnson $L A$, June $C H$. Driving gene-engineered $T$ cell immunotherapy of cancer. Cell Res. 2017;27(1):38-58. https://doi.org/10.1038/cr.2016. 154.

29. Wayne AS, Giralt S, Kröger N, Bishop MR. Proceedings from the National Cancer Institute's Second International Workshop on the Biology, Prevention, and Treatment of Relapse after Hematopoietic Stem Cell Transplantation: introduction. Biol Blood Marrow Transplant. 2013;19(11):1534-6. https://doi.org/10.1016/j.bbmt.2013.08.016.

30. Boopathy GTK, Hong W. Role of Hippo Pathway-YAP/TAZ Signaling in Angiogenesis. Front Cell Dev Biol. 2019;7:49. https://doi.org/10.3389/ fcell.2019.00049.

31. Heng BC, Zhang X, Aubel D, Bai Y, Li X, Wei Y, Fussenegger M, Deng $X$. An overview of signaling pathways regulating YAP/TAZ activity. Cell Mol Life Sci. 2021;78(2):497-512. https://doi.org/10.1007/ s00018-020-03579-8.

32. Callus BA, Finch-Edmondson ML, Fletcher S, Wilton SD. YAPping about and not forgetting TAZ. FEBS Lett. 2019;593(3):253-76. https://doi.org/ 10.1002/1873-3468.13318.

33. Park JH, Shin JE, Park HW. The Role of Hippo Pathway in Cancer Stem Cell Biology. Mol Cells. 2018;41(2):83-92. https://doi.org/10.14348/ molcells.2018.2242.

34. Karvonen H, Barker H, Kaleva L, Niininen W, Ungureanu D. Molecular Mechanisms Associated with ROR1-Mediated Drug Resistance: Crosstalk with Hippo-YAP/TAZ and BMI-1 Pathways. Cells. 2019;8(8):812. https://doi.org/10.3390/cells8080812.

35. Xu Z, Wang H, Gao L, Zhang H, Wang X. YAP Levels Combined with Plasma CEA Levels Are Prognostic Biomarkers for Early-Clinical-Stage Patients of Colorectal Cancer. Biomed Res Int. 2019;2019:2170830. https://doi.org/10.1155/2019/2170830.

36. Qu Y, Zhang L, Wang J, Chen P, Jia Y, Wang C, Yang W, Wen Z, Song Q, Tan B, Cheng Y. Yes-associated protein (YAP) predicts poor prognosis and regulates progression of esophageal squamous cell cancer through epithelial-mesenchymal transition. Exp Ther Med. 2019;18(4):2993-3001. https://doi.org/10.3892/etm.2019.7896.

37. Shu B, Zhai M, Miao X, He C, Deng C, Fang Y, Luo M, Liu L, Liu S. Serotonin and YAP/VGLL4 Balance Correlated with Progression and Poor Prognosis of Hepatocellular Carcinoma. Sci Rep. 2018:8(1):9739. https://doi.org/10.1038/s41598-018-28075-9.

38. Bouvier C, Macagno N, Nguyen Q, Loundou A, Jiguet-Jiglaire C, Gentet JC, Jouve JL, Rochwerger A, Mattei JC, Bouvard D, Salas S. Prognostic value of the Hippo pathway transcriptional coactivators YAP/TAZ and $\beta 1$-integrin in conventional osteosarcoma. Oncotarget. 2016;7(40):64702-10. https://doi.org/10.18632/oncotarget.11876.

39. Steinhardt AA, Gayyed MF, Klein AP, Dong J, Maitra A, Pan D, Montgomery EA, Anders RA. Expression of Yes-associated protein in common solid tumors. Hum Pathol. 2008;39(11):1582-9. https://doi.org/ 10.1016/j.humpath.2008.04.012.

40. Yu SJ, Hu JY, Kuang XY, Luo JM, Hou YF, Di GH, Wu J, Shen ZZ, Song HY, Shao ZM. MicroRNA-200a promotes anoikis resistance and metastasis by targeting YAP1 in human breast cancer. Clin Cancer Res. 2013;19(6):1389-99. https://doi.org/10.1158/1078-0432.CCR-12-1959.

41. Lapi E, Di Agostino S, Donzelli S, Gal H, Domany E, Rechavi G, Pandolfi PP, Givol D, Strano S, Lu X, Blandino G. PML, YAP, and p73 are components of a proapoptotic autoregulatory feedback loop. Mol Cell. 2008;32(6):803-14. https://doi.org/10.1016/j.molcel.2008.11.019.
42. Wang Y, Xie C, Li Q, Xu K, Wang E. Clinical and prognostic significance of Yes-associated protein in colorectal cancer. Tumour Biol. 2013;34(4):2169-74. https://doi.org/10.1007/s13277-013-0751-X.

43. Xia Y, Chang T, Wang Y, Liu Y, Li W, Li M, Fan HY. YAP promotes ovarian cancer cell tumorigenesis and is indicative of a poor prognosis for ovarian cancer patients. PLoS One. 2014;9(3):e91770 https:// doi.org/10.1371/journal.pone.0091770 (Erratum. In: PLoS One. 2016;11(3):e0152712)

44. Barry ER, Morikawa T, Butler BL, Shrestha K, de la Rosa R, Yan KS, Fuchs CS, Magness ST, Smits R, Ogino S, Kuo CJ, Camargo FD. Restriction of intestinal stem cell expansion and the regenerative response by YAP. Nature. 2013;493(7430):106-10. https://doi.org/10.1038/nature1 1693.

45. Sun Z, Xu R, Li X, Ren W, Ou C, Wang Q, Zhang H, Zhang X, Ma J, Wang H, Li G. Prognostic Value of Yes-Associated Protein 1 (YAP1) in Various Cancers: A Meta-Analysis. PLoS One. 2015;10(8):e0135119. https://doi.org/10.1371/journal.pone.0135119.

46. Totaro A, Panciera T, Piccolo S. YAP/TAZ upstream signals and downstream responses. Nat Cell Biol. 2018;20(8):888-99. https://doi.org/10. 1038/s41556-018-0142-Z.

47. Guo Y, Cui J, Ji Z, Cheng C, Zhang K, Zhang C, Chu M, Zhao Q, Yu Z, Zhang Y, Fang YX, Gao WQ, Zhu HH. miR-302/367/LATS2/YAP pathway is essential for prostate tumor-propagating cells and promotes the development of castration resistance. Oncogene. 2017:36(45):6336-47. https://doi.org/10.1038/onc.2017.240.

48. Varelas X. The Hippo pathway effectors TAZ and YAP in development, homeostasis and disease. Development. 2014;141(8):1614-26. https://doi.org/10.1242/dev.102376.

49. Hansen CG, Moroishi T, Guan KL. YAP and TAZ: a nexus for Hippo signaling and beyond. Trends Cell Biol. 2015;25(9):499-513. https:// doi.org/10.1016/j.tcb.2015.05.002.

50. Yu FX, Zhao B, Guan KL. Hippo Pathway in Organ Size Control, Tissue Homeostasis, and Cancer. Cell. 2015;163(4):811-28. https://doi.org/ 10.1016/j.cell.2015.10.044.

51. Varelas X, Sakuma R, Samavarchi-Tehrani P, Peerani R, Rao BM, Dembowy J, Yaffe MB, Zandstra PW, Wrana JL. TAZ controls Smad nucleocytoplasmic shuttling and regulates human embryonic stemcell self-renewal. Nat Cell Biol. 2008;10(7):837-48. https://doi.org/10. 1038/ncb1748.

52. Chavali M, Klingener M, Kokkosis AG, Garkun Y, Felong S, Maffei A, Aguirre A. Non-canonical Wnt signaling regulates neural stem cell quiescence during homeostasis and after demyelination. Nat Commun. 2018;9(1):36. https://doi.org/10.1038/s41467-017-02440-0.

53. Wang LT, Lin MH, Liu KY, Chiou SS, Wang SN, Chai CY, Tseng LW, Chiou HC, Wang HC, Yokoyama KK, Hsu SH, Huang SK. WLS/wntless is essential in controlling dendritic cell homeostasis via a WNT signalingindependent mechanism. Autophagy. 2021;14:1-16. https://doi.org/ 10.1080/15548627.2021.1907516.

54. Hétu-Arbour R, Tlili M, Bandeira Ferreira FL, Abidin BM, Kwarteng EO, Heinonen KM. Cell-intrinsic Wnt4 promotes hematopoietic stem and progenitor cell self-renewal. Stem Cells. 2021;39(9):1207-20. https:// doi.org/10.1002/stem.3385.

55. Krishnan M, Kumar S, Kangale LJ, Ghigo E, Abnave P. The act of controlling adult stem cell dynamics: Insights from animal models. Biomolecules. 2021;11(5):667. https://doi.org/10.3390/biom1 10506 67.

56. Yao Y, Li F, Huang J, Jin J, Wang H. Leukemia stem cell-bone marrow microenvironment interplay in acute myeloid leukemia development. Exp Hematol Oncol. 2021;10(1):39. https://doi.org/10.1186/ s40164-021-00233-2.

57. Soares-Lima SC, Pombo-de-Oliveira MS, Carneiro FRG. The multiple ways Wnt signaling contributes to acute leukemia pathogenesis. J Leukoc Biol. 2020;108(4):1081-99. https://doi.org/10.1002/JLB.2MR04 20-707R.

58. Liu Z, Wang P, Wold EA, Song Q, Zhao C, Wang C, Zhou J. Small-Molecule Inhibitors Targeting the Canonical WNT Signaling Pathway for the Treatment of Cancer. J Med Chem. 2021;64(8):4257-88. https:// doi.org/10.1021/acs.jmedchem.0c01799.

59. Eiring AM, Khorashad JS, Anderson DJ, Yu F, Redwine HM, Mason CC, Reynolds KR, Clair PM, Gantz KC, Zhang TY, Pomicter AD, Kraft $\mathrm{IL}$, Bowler AD, Johnson K, Partlin MM, O'Hare T, Deininger MW. $\beta$-Catenin is required for intrinsic but not extrinsic BCR-ABL1 
kinase-independent resistance to tyrosine kinase inhibitors in chronic myeloid leukemia. Leukemia. 2015;29(12):2328-37. https:// doi.org/10.1038/leu.2015.196.

60. Jin B, Wang C, Li J, Du X, Ding K, Pan J. Anthelmintic Niclosamide Disrupts the Interplay of p65 and FOXM1/ $\beta$-catenin and Eradicates Leukemia Stem Cells in Chronic Myelogenous Leukemia. Clin Cancer Res. 2017;23(3):789-803. https://doi.org/10.1158/1078-0432.CCR-16-0226.

61. Varelas X, Miller BW, Sopko R, Song S, Gregorieff A, Fellouse FA, Sakuma R, Pawson T, Hunziker W, McNeill H, Wrana JL, Attisano L. The Hippo pathway regulates Wnt/beta-catenin signaling. Dev Cell. 2010;18(4):579-91. https://doi.org/10.1016/j.devcel.2010.03.007.

62. Azzolin L, Zanconato F, Bresolin S, Forcato M, Basso G, Bicciato S, Cordenonsi M, Piccolo S. Role of TAZ as mediator of Wnt signaling. Cell. 2012;151(7):1443-56. https://doi.org/10.1016/j.cell.2012.11.027.

63. Staal FJ, Famili F, Garcia Perez L, Pike-Overzet K. Aberrant wnt signaling in Leukemia. Cancers (Basel). 2016;8(9):78. https://doi.org/10. 3390/cancers8090078.

64. Takahashi T, Shiraishi A, Murata J. The Coordinated Activities of nAChR and Wnt Signaling Regulate Intestinal Stem Cell Function in Mice. Int J Mol Sci. 2018;19(3):738. https://doi.org/10.3390/ijms1 9030738.

65. Yang $X$, Yang C, Farberman A, Rideout TC, de Lange CF, France J, Fan MZ The mammalian target of rapamycin-signaling pathway in regulating metabolism and growth. J Anim Sci. 2008;86(14 Suppl):E36-50. https:// doi.org/10.2527/jas.2007-0567.

66. Castedo M, Ferri KF, Kroemer G. Mammalian target of rapamycin (mTOR): pro- and anti-apoptotic. Cell Death Differ. 2002;9(2):99-100. https://doi.org/10.1038/sj.cdd. 4400978.

67. Liang K, Zhou G, Zhang Q, Li J, Zhang C. Expression of hippo pathway in colorectal cancer. Saudi J Gastroenterol. 2014;20(3):188-94. https://doi. org/10.4103/1319-3767.133025.

68. Artinian N, Cloninger C, Holmes B, Benavides-Serrato A, Bashir T, Gera J. Phosphorylation of the Hippo Pathway Component AMOTL2 by the mTORC2 Kinase Promotes YAP Signaling, Resulting in Enhanced Glioblastoma Growth and Invasiveness. J Biol Chem. 2015;290(32):19387401. https://doi.org/10.1074/jbc.M115.656587.

69. Parker J, Struhl G. Scaling the Drosophila Wing:TOR-Dependent Target Gene Access by the Hippo Pathway Transducer Yorkie. PLoS Biol. 2015;13(10):e1002274. https://doi.org/10.1371/journal.pbio.1002274.

70. Degirmenci U, Wang M, Hu J. Targeting aberrant RAS/RAF/MEK/ERK signaling for cancer therapy. Cells. 2020;9(1):198. https://doi.org/10. 3390/cells9010198.

71. Kishtagari A, Levine RL, Viny AD. Driver mutations in acute myeloid leukemia. Curr Opin Hematol. 2020;27(2):49-57. https://doi.org/10.1097/ $\mathrm{MOH} .0000000000000567$.

72. Rocca S, Carrà G, Poggio P, Morotti A, Brancaccio M. Targeting few to help hundreds: JAK, MAPK and ROCK pathways as druggable targets in atypical chronic myeloid leukemia. Mol Cancer. 2018;17(1):40. https:// doi.org/10.1186/s12943-018-0774-4

73. Feng R, Gong J, Wu L, Wang L, Zhang B, Liang G, Zheng H, Xiao H. MAPK and Hippo signaling pathways crosstalk via the RAF-1/MST-2 interaction in malignant melanoma. Oncol Rep. 2017;38(2):1199-205. https:// doi.org/10.3892/or.2017.5774.

74. Ma S, Meng Z, Chen R, Guan KL. The Hippo Pathway: Biology and Pathophysiology. Annu Rev Biochem. 2019;88:577-604. https://doi.org/ 10.1146/annurev-biochem-013118-111829.

75. Hasegawa K, Fujii S, Matsumoto S, Tajiri Y, Kikuchi A, Kiyoshima T. YAP signaling induces PIEZO1 to promote oral squamous cell carcinoma cell proliferation. J Pathol. 2021;253(1):80-93. https://doi.org/10.1002/path. 5553.

76. Yuan J, Dong X, Yap J, Hu J. The MAPK and AMPK signalings: interplay and implication in targeted cancer therapy. J Hematol Oncol. 2020;13(1):113. https://doi.org/10.1186/s13045-020-00949-4.

77. Ferreira AR, Ramalho AC, Marques M, Ribeiro D. The Interplay between Antiviral Signalling and Carcinogenesis in Human Papillomavirus Infections. Cancers (Basel). 2020;12(3):646. https://doi.org/10.3390/cance rs12030646.

78. Chen Z, Li S, Mo J, Hawley E, Wang Y, He Y, Brosseau JP, Shipman T, Clapp DW, Carroll TJ, Le LQ. Schwannoma development is mediated by Hippo pathway dysregulation and modified by RAS/MAPK signaling. JCI Insight. 2020;5(20): https://doi.org/10.1172/jci.insight.141514.
79. Duda P, Akula SM, Abrams SL, Steelman LS, Martelli AM, Cocco L, Ratti S, Candido S, Libra M, Montalto G, Cervello M, Gizak A, Rakus D, McCubrey JA. Targeting GSK3 and Associated Signaling Pathways Involved in Cancer. Cells. 2020;9(5):1110. https://doi.org/10.3390/cells9051110.

80. Mohammadi S, Arefnezhad R, Danaii S, Yousefi M. New insights into the core Hippo signaling and biological macromolecules interactions in the biology of solid tumors. Biofactors. 2020;46(4):514-30. https://doi.org/ 10.1002/biof.1634.

81. Allegra A, Pioggia G, Innao V, Musolino C, Gangemi S. New Insights into YES-Associated Protein Signaling Pathways in Hematological Malignancies: Diagnostic and Therapeutic Challenges. Cancers (Basel). 2021;13(8):1981. https://doi.org/10.3390/cancers13081981.

82. Vigneau AL, Rico C, Boerboom D, Paquet M. Statins downregulate YAP and TAZ and exert anti-cancer effects in canine mammary tumor cells. Vet Comp Oncol. 2021;. https://doi.org/10.1111/vco.12789.

83. Masliantsev K, Karayan-Tapon L, Guichet PO. Hippo signaling pathway in gliomas. Cells. 2021;10(1):184. https://doi.org/10.3390/cells10010184.

84. Höffken V, Hermann A, Pavenstädt $H$, Kremerskothen J. WWC proteins: Important regulators of hippo signaling in cancer. Cancers (Basel). 2021;13(2):306. https://doi.org/10.3390/cancers13020306.

85. Kovar H, Bierbaumer L, Radic-Sarikas B. The YAP/TAZ Pathway in Osteogenesis and Bone Sarcoma Pathogenesis. Cells. 2020;9(4):972. https:// doi.org/10.3390/cells9040972.

86. Gholami M, Mirfakhraie R, Movafagh A, Jalaeekhoo H, Kalahroodi R, Zare-Abdollahi D, Zare-Karizi S. The expression analysis of LATS2 gene in de novo AML patients. Med Oncol. 2014;31(5):961. https://doi.org/10. 1007/s12032-014-0961-0.

87. Jiménez-Velasco A, Román-Gómez J, Agirre X, Barrios M, Navarro G, Vázquez I, Prósper F, Torres A, Heiniger A. Downregulation of the large tumor suppressor 2 (LATS2/KPM) gene is associated with poor prognosis in acute lymphoblastic leukemia. Leukemia. 2005;19(12):2347-50. https://doi.org/10.1038/sj.leu.2403974.

88. Han Y. Analysis of the role of the Hippo pathway in cancer. J Transl Med. 2019;17(1):116. https://doi.org/10.1186/s12967-019-1869-4.

89. Que K, Tong Y, Que G, Li L, Lin H, Huang S, Wang R, Tang L. Downregulation of miR-874-3p promotes chemotherapeutic resistance in colorectal cancer via inactivation of the Hippo signaling pathway. Oncol Rep. 2017;38(6):3376-86. https://doi.org/10.3892/or.2017.6041.

90. Hu Y, Yang C, Yang S, Cheng F, Rao J, Wang X. miR-665 promotes hepatocellular carcinoma cell migration, invasion, and proliferation by decreasing Hippo signaling through targeting PTPRB. Cell Death Dis. 2018;9(10):954. https://doi.org/10.1038/s41419-018-0978-y.

91. Zhu R, Zhao W, Fan F, Tang L, Liu J, Luo T, Deng J, Hu Y. A 3-miRNA signature predicts prognosis of pediatric and adolescent cytogenetically normal acute myeloid leukemia. Oncotarget. 2017;8(24):38902-13. https://doi.org/10.18632/oncotarget.17151.

92. Hu C, Yu M, Li C, Wang Y, Li X, Ulrich B, Su R, Dong L, Weng H, Huang $H$, Jiang $X$, Chen J, Jin J. miR-550-1 functions as a tumor suppressor in acute myeloid leukemia via the hippo signaling pathway. Int J Biol Sci. 2020;16(15):2853-67. https://doi.org/10.7150/ijbs.44365.

93. Zhong L, Li Y, Xiong L, Wang W, Wu M, Yuan T, Yang W, Tian C, Miao Z, Wang T, Yang S. Small molecules in targeted cancer therapy: advances, challenges, and future perspectives. Signal Transduct Target Ther. 2021;6(1):201. https://doi.org/10.1038/s41392-021-00572-w.

94. Oku Y, Nishiya N, Shito T, Yamamoto R, Yamamoto Y, Oyama C, Uehara Y. Small molecules inhibiting the nuclear localization of YAP/TAZ for chemotherapeutics and chemosensitizers against breast cancers. FEBS Open Bio. 2015;5:542-9. https://doi.org/10.1016/j.fob.2015.06.007.

95. Wang C, Zhu X, Feng W, Yu Y, Jeong K, Guo W, Lu Y, Mills GB. Verteporfin

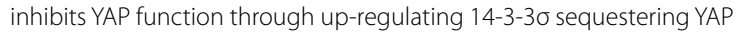
in the cytoplasm. Am J Cancer Res. 2015;6(1):27-37.

96. Das A, Fischer RS, Pan D, Waterman CM. YAP Nuclear Localization in the Absence of Cell-Cell Contact Is Mediated by a Filamentous Actindependent, Myosin II- and Phospho-YAP-independent Pathway during Extracellular Matrix Mechanosensing. J Biol Chem. 2016;291 (12):6096110. https://doi.org/10.1074/jbc.M115.708313.

97. Mo JS, Yu FX, Gong R, Brown JH, Guan KL. Regulation of the HippoYAP pathway by protease-activated receptors (PARs). Genes Dev. 2012;26(19):2138-43. https://doi.org/10.1101/gad.197582.112.

98. Galli GG, Carrara M, Yuan WC, Valdes-Quezada C, Gurung B, PepeMooney B, Zhang T, Geeven G, Gray NS, de Laat W, Calogero RA, 
Camargo FD. YAP Drives Growth by Controlling Transcriptional Pause Release from Dynamic Enhancers. Mol Cell. 2015;60(2):328-37. https:// doi.org/10.1016/j.molcel.2015.09.001.

99. Wang X, Kaczor-Urbanowicz KE, Wong DT. Salivary biomarkers in cancer detection. Med Oncol. 2017;34(1):7. https://doi.org/10.1007/ s12032-016-0863-4.

100. Yu FX, Zhang Y, Park HW, Jewell JL, Chen Q, Deng Y, Pan D, Taylor SS, Lai ZC, Guan KL. Protein kinase A activates the Hippo pathway to modulate cell proliferation and differentiation. Genes Dev. 2013;27(11):1223-32. https://doi.org/10.1101/gad.219402.113.

101. Bao Y, Nakagawa K, Yang Z, Ikeda M, Withanage K, Ishigami-Yuasa M, Okuno Y, Hata S, Nishina H, Hata Y. A cell-based assay to screen stimulators of the Hippo pathway reveals the inhibitory effect of dobutamine on the YAP-dependent gene transcription. J Biochem. 2011;150(2):199208. https://doi.org/10.1093/jb/mvr063.

102. Seo J, Kim J. Regulation of Hippo signaling by actin remodeling. BMB Rep. 2018;51(3):151-6. https://doi.org/10.5483/bmbrep.2018.51.3.012.

103. Guo L, Teng L. YAP/TAZ for cancer therapy: opportunities and challenges (review). Int J Oncol. 2015;46(4):1444-52. https://doi.org/10. 3892/ijo.2015.2877.

104. Marsola APZC, Simões BP, Palma LC, Berzoti-Coelho MG, Burin SM, de Castro FA. Expression of Hippo signaling pathway and Aurora kinase genes in chronic myeloid leukemia. Med Oncol. 2018;35(3):26. https:// doi.org/10.1007/s12032-018-1079-6.

105. Safari S, Movafagh A, Zare-Adollahi D, Ghadiani M, Riazi-Isfahani S, Safavi-Naini N, Omrani MD. MST1/2 and YAP1 gene expression in acute myeloid leukemia. Leuk Lymphoma. 2014;55(9):2189-91. https://doi. org/10.3109/10428194.2013.867493.

106. Kim TS, Lee DH, Kim SK, Shin SY, Seo EJ, Lim DS. Mammalian sterile 20-like kinase 1 suppresses lymphoma development by promoting faithful chromosome segregation. Cancer Res. 2012;72(20):5386-95. https://doi.org/10.1158/0008-5472.CAN-11-3956.

107. Hartmann EM, Campo E, Wright G, Lenz G, Salaverria I, Jares P, Xiao W, Braziel RM, Rimsza LM, Chan WC, Weisenburger DD, Delabie J, Jaffe ES, Gascoyne RD, Dave SS, Mueller-Hermelink HK, Staudt LM, Ott G, Beà S, Rosenwald A. Pathway discovery in mantle cell lymphoma by integrated analysis of high-resolution gene expression and copy number profiling. Blood. 2010;116(6):953-61. https://doi.org/10.1182/ blood-2010-01-263806.

108. Wang G, Yu X, Xia J, Sun J, Huang H, Liu Y. MicroRNA-9 restrains the sharp increase and boost apoptosis of human acute myeloid leukemia cells by adjusting the Hippo/YAP signaling pathway. Bioengineered. 2021;12(1):2906-14. https://doi.org/10.1080/21655979.2021.1915727.

109. Chorzalska A, Kim JF, Roder K, Tepper A, Ahsan N, Rao RSP, Olszewski AJ, Yu X, Terentyev D, Morgan J, Treaba DO, Zhao TC, Liang O, Gruppuso PA, Dubielecka PM. Long-Term Exposure to Imatinib Mesylate Downregulates Hippo Pathway and Activates YAP in a Model of Chronic Myelogenous Leukemia. Stem Cells Dev. 2017;26(9):656-77. https://doi. org/10.1089/scd.2016.0262.

110. Yoshida M, Horiguchi H, Kikuchi S, Iyama S, Ikeda H, Goto A, Kawano Y, Murase K, Takada K, Miyanishi K, Kato J, Kobune M. miR-7977 inhibits the Hippo-YAP signaling pathway in bone marrow mesenchymal stromal cells. PLoS One. 2019;14(3):e0213220. https://doi.org/10.1371/journ al.pone.0213220.

\section{Publisher's Note}

Springer Nature remains neutral with regard to jurisdictional claims in published maps and institutional affiliations.

Ready to submit your research? Choose BMC and benefit from:

- fast, convenient online submission

- thorough peer review by experienced researchers in your field

- rapid publication on acceptance

- support for research data, including large and complex data types

- gold Open Access which fosters wider collaboration and increased citations

- maximum visibility for your research: over $100 \mathrm{M}$ website views per year

At BMC, research is always in progress.

Learn more biomedcentral.com/submissions 